\title{
THEORY ADRIFT: \\ THE MATTER OF ARCHAEOLOGICAL THEORIZING
}

PÓRA PÉTURSDÓTTIR \& BJøRNAR OLSEN

Póra Pétursdóttir ${ }^{1}$, Department of Archaeology, History, Religion and Theology, UiT The Arctic University of Norway, Tromsø, Norway. Email: thora.petursdottir@uit.no

Bjørnar Olsen, Department of Archaeology, History, Religion and Theology, UiT The Arctic University of Norway, Tromsø, Norway. Email: bjornar.olsen@uit.no

\section{BIOGRAPHICAL NOTES:}

Póra Pétursdóttir is researcher in the project Unruly Heritage: An Archaeology of the Anthropocene at UiT - The Arctic University of Norway. Her research interests lie within archaeology of the contemporary past, critical heritage studies and archaeological theory and method, touching on issues of e.g. the materiality of memory, ethics of things, affect and heritage experiences, and the particularities of archaeological story telling. Together with Bjørnar Olsen, Pétursdóttir is the editor of Ruin Memories: Materialities, Aesthetics and the Archaeology of the Recent Past (Routledge, 2014), and she is currently editing a volume on critical heritage studies, together with Torgeir Rinke Bangstad, entitled Heritage Ecologies (Routledge, forthcoming). Póra's current research is focused on drift beaches and drift matter in the North Atlantic, in particular in Northern Norway and Iceland.

Bjørnar Julius Olsen is professor in archaeology at UiT - The Arctic University of Norway. Since the early 1980s, he has worked with northern and Sámi archaeology as well with theoretical issues in archaeology and the humanities. Apart from these fields his current research interests include contemporary archaeology, modern ruins, material memory and thing theory. He has led several research projects on contemporary archaeology, including the newly started Unruly Heritage: An Archaeology of the Anthropocene. Among his latest books are In Defense of Things (2010); Persistent Memories (2010, with E. Andreassen and H. Bjerck); Archaeology: The Discipline of Things (2012, with M. Shanks, T. Webmoor and C. Witmore), and Ruin Memories: Materialities, Aesthetics and the Archaeology of the Recent Past (2014, editor with P. Pétursdóttir).

\footnotetext{
${ }^{1}$ Corresponding author address: Póra Pétursdóttir, AHR, UiT The Arctic University of Norway, Postbox 6050 Langnes, 9037 Troms $\varnothing$, Norge.
} 


\section{ACKNOWLEDGEMENTS}

We express our gratitude to The Norwegian Research Council for financing our research and fieldwork in the north, through grants provided for the projects Ruin Memories (2009-2013) and Object Matters (2015-2018). This article was written during our stay at the Centre for Advanced Study in Oslo, 2016-2017. We thank the centre and our colleagues for providing such an academically stimulating environment. Lastly, we thank the three anonymous reviewers for their comments.

\section{ABSTRACT}

At a possible transition towards a "flat", post-human or new-materialist environment, many have suggested that archaeological theory and theorizing is changing course; turning to metaphysics; leaning towards the sciences; or, even is declared dead. Resonating with these concerns, and drawing on our fieldwork on a northern driftwood beach, this article suggests the need to rethink fundamental notions of what theory is - its morphological being - and how it behaves and takes form. Like drift matter on an Arctic shore, theories are adrift. They are not natives of any particular territory, but nomads in a mixed world. While they are themselves of certain weight and figure, it matters what things they bump into, become entangled with, and moved by. Based on this, we argue that theories come unfinished and fragile. Much like things stranding on a beach they don't simply "add up" but can become detached, fragmented, turned and transfigured. Rather than seeing this drift as rendering them redundant and out of place, it is this nomadism and "weakness" that sustains them and keeps them alive.

KEYWORDS: Archaeological theory, theory building, morphology of theory, object-oriented philosophy, epistemology, ontology, 


\section{THEORY ADRIFT: \\ THE MATTER OF ARCHAEOLOGICAL THEORIZING}

PÓRA PÉTURSDÓTTIR \& BJøRNAR OLSEN

\section{INTRODUCTION}

Working on the coast of Arctic Norway, returning again and again to the same place, the same shore, we have become intrigued by one phenomenon in particular; the wealth of stuff accumulating along the intertidal zone of this small inlet. Driftwood, worked wood, pallets, buoys, nets, floats, fish boxes, ropes, lines, buckets, shovels, footballs, tennis rackets, toy cars, gloves, helmets, shoes, sandals, boots, light bulbs, toothbrushes, life-wests, overalls, tuna cans, Christmas trees, bottles, whale carcasses, oil barrels, bird bones, ice-cream boxes, seaweed, garden chairs. Gathering in a thick wavelike ridge, stretching from one end of the cove to the other, the material brakes on land, tumbles and tangles in a manner that appears impossible to unravel. Thrown together, things bump into each other in weirdly unexpected ways, forming unimaginable coalitions and fusions. And in the depths of this amalgam things become pressed together, fractured between beach pebbles, to lastly endure as brightly coloured freckles in the beach sediments.

Repeatedly encountering this dazing wave of stranded material has been both terrifying and intriguing. It concurrently draws and resists our archaeological gaze. Familiar and strange its autonomy, post-human drift and gathering insinuatingly defies accustomed archaeological notions of locality, cultural context and meaning. Its utter and, indeed, very weighty presence scorns aspirations of refitting and retracing. Not because it is necessarily impossible, but because what appears most authentic about this stuff is not its possible naming, origin, past function or human embracement, but the way it has drifted out of just those associations, and become fragmented and transmuted in ways not foreseen. Then, how should we respond to these things in their tumbled articulation? What forms of knowing do they make possible? Or put differently, how do you approach a material swell of this sort - and how does its unfathomable bulging affect your advancing?

Interestingly, revisiting this odd material over and over again, what at first appeared as its profound difference from an archaeological context has increasingly revealed itself as affinities and accentuations. Though here manifested in more extreme ways, characteristics such as fragmentation, 
displacement, withdrawal, coincidence, entanglement, are in essence features encountered also in more familiar archaeological settings. The difference is more one of degree, than of kind. And, thus, what this abounding breaker recalls is also an aspect of archaeological being that rarely survives interpretation and theoretical encounters. An alterity that theoretical filtration rather repeals and compensates for, but which here, in this particular setting of material diaspora, appears as a less likely and even futile way to proceed. As such, these beach assemblages also bring to light some of the difference and even incommensurability between our material and the theoretical bodies we employ to interpret it; that is, the difference between the "wild", scattered and incomplete nature of archaeological things and the expected coherency, wholeness and rational logic of theory.

But what if one took seriously as a real and significant trait the fragmented and "unruly" aspect of our material record and its reluctance to obediently bow to the logic and coherency of theory? What could we learn from this resistance and from the ways things articulate themselves upon encounter? What kind of theorizing would allow inclusion of this experience and grounded knowledge in telling and interpretations? And what kind of theory might itself be open to modification, and even shattering, as a consequence of such archaeological encounters? In other words, is it possible to imagine theory as something else than hitherto conceived, something that comes unfinished and fragile? And therefore, perhaps, better prepared for embracing and interacting with these very particular aspects of the archaeological?

$<<$ INSERT FIGURE 1 ABOUT HERE $>>$

Fig. 1 A wave of drift matter in Eidsbukta, Finnmark, Norway

Today, in the extended aftermath of post-processual archaeology, at the possible transition towards a "flat'”, post-human or new-materialist environment, many have suggested that archaeological theory and theorizing is changing course; turning to metaphysics; leaning towards the sciences; or, even is declared dead (e.g. Bintliff and Peirce, 2011; Alberti et al., 2013; Kristiansen, 2014; Lucas, 2015; Thomas, 2015a, 2015b, Harris and Chipolla 2017). Resonating with these concerns, and drawing on our fieldwork on the coast of Arctic Norway, this article suggests the need to rethink fundamental notions of what theory is, how it behaves and takes form, how it may be applied and, even more importantly, subtended and furnished. Drawing on current debates it also resonates with a deeper lineage of theoretical conversation in archaeology, and recurring themes such as the discrepancies between theory and practice, between theory building and theory borrowing, between top-down and bottom-up theorizing, and between the limits of case based theory and the aspirations for an extended life of archaeological theory beyond disciplinary boundaries. It should be 
emphasized, however, that our ambition is not to provide any detailed discussion of what previously has been said about these issues, or to address all the different kinds of theory used in archaeology today. Deliberately deviating from such standard tropes of theoretical archaeological narration, our aim here is to sketch an alternative argument where archaeological things and experiences are centre stage. And by attempting a more positive perspective on what often is viewed as fallacies of archaeology's relationship with theory, we will seek to explore the possible rewards of its encounter with the archaeological, how theory may be fragmented, transformed, repaired and/or reassembled, and thereby also provide new potentials for a tradition and art of borrowing.

\section{PLACING THE ARGUMENT}

Let us begin by trying to situate our course a little more explicitly - and in that endeavour refer to a conversation we had recently. Sitting in a noisy pub in central Oslo on a late Friday night, together with Levi Bryant, one of the prominent spokesmen of object-oriented ontology, and talking about archaeological fieldwork of all things, he says; "Well, you know, philosophy is a parasitic discipline." We went silent for a second. How many times haven't we heard the same said about archaeology? About its dependency on theoretical supplies from anthropology or philosophy. Then he added, "I mean, we don't do fieldwork". Again, we were silent for a second, thinking, well, how interesting, and how very true - possibly! But what does this actually imply? And what is being insinuated when archaeology is accused of the same?

In a recent article Gavin Lucas (2015) makes a convincing go at countering the anxieties archaeologists appear to have when it comes to "borrowing" theory. Crucial to his argument is the mobility of theory and theorizing, as exemplified by the dispersed use of "concept-metaphors" such as identity, gender and agency. These are concepts used in cross-disciplinary theorizing, and are characterized by their inherent vagueness and weak ontological commitment, which thus at the same time both help their mobility as well as make them dependent on being articulated through specific contexts and situated empirical observations. Drawing rather on a morphological register, we believe it is important also to think about what theory is and where it is, in terms of its possible concrete "amongstness". This is not just to say that we need to think about how theory is applied and articulated - but, and far more significant, how it is supplemented, worked on, and cared for. In other words, our concern is not how theory hovers and moves above a disciplinary geography, but how it is morphologically part of the actual landscape, how it moves among things and, importantly, becomes moved by them. 
This, we believe, is especially important for archaeologists who consistently work with theory in relation to concrete landscapes and things, but also more generally for how to understand theory and its relation to "the real". This relation was recently addressed in a blog post by Levi Bryant $(2016)^{2}$. Here, Bryant expresses a distrust in theories that do not employ a rich repertoire of "examples", as this, he worries, may render them "unmoored from anything in the world" and release them of the responsibility of really explaining anything of this world. Bryant goes further to claim that the example is not merely important and formative in retrospect, but also with respect to the future of theory and theorizing. He proceeds by addressing fellow object-oriented philosopher Graham Harman, asking:

How about Harman? His favourite examples are fire, cotton, and hammers. How might these archetypal examples inform his entire conception of objects? Would that theory be different if one chose a flower or waves or a factory? When a theorist wishes to write about architecture and uses the home as their go to example, how does that example come to inform their entire theory of architecture? Examples express intuitions about the nature of broader categories like "being", "knowledge", "truth", "normativity", etc. They are not secondary, but are at the core of theoretical work.

This is indeed interesting, though one might ask whether the term "example" is the right one to use in this context, or whether it rather misleads and downgrades the significance of the relation being underlined? Possibly. In any case, this assertion - of the fundamental role of theoretical engagement with the real - is at the core of our argument in this paper.

To explain a little further, let us have a look at Harman's recent book, Immaterialism (2016), a kind of manifesto for his object-oriented philosophy, where the questions Bryant asks gain even further actuality. Putting hammers, cotton and fire to the side, Harman here employs the $17^{\text {th }}$ century Dutch East India Company (VOC) as an example of an "object", in order to outline central notions and concepts of his philosophy. Based on an exclusively historical study of the VOC and its documented development during its period of operation (1602-1795), Harman constructs an object theory, or an 000 methodology, with claimed general relevance to the study of any object ${ }^{3}$. This also involves general guidelines related to things' being, their relations, and the critical phases of symbiosis (including death) in their careers (Harman, 2016: 77-85). Proceeding

\footnotetext{
2 https://larvalsubjects.wordpress.com/2016/07/27/examples/

${ }^{3}$ Harman sometimes uses the notion "social objects" $(2016: 37,84-85,88)$ but without defining what is meant by this term and to what extent it differs from other, non-social objects.
} 
from Bryant's interesting and radical line of argument it feels compelling to ask: How would an archaeological approach to the VOC, which obviously also included wrecked and sunken ships, released ballast, deserted harbours, distributed goods and derelict fortresses, have affected his theory? Would a concern with these tactile components of the VOC, with abandoned and derelict things, not have led to a somewhat different conception of objects and object careers, than one based on written records of a well-functioning and networked "social" VOC? And what would have happened to Harman's conception of objects if he chose as his "go to example" ruined herring factories or beach assemblages in the north Atlantic? In accordance with Bryant, we would suggest that such examples cannot be seen as secondary to theory, but as a constructive and integral part of it. One is neither on top of the other nor extracted from the other.

What constitutes the archaeological - like the swell of drift matter on a beach provides abundant evidence of things “that don't just add up but take on a life of their own as problems of thought" (Stewart, 2008: 72). Unlike common philosophical examples, where familiar, singular and predefined things are selected to illustrate a certain argument and way of reasoning, archaeology is committed to things that presence themselves in ways that defy such selectivity and control. Randomly surviving in messy assemblages, soiled and broken, they mostly address us without the usual crust of cultural meaning. Archaeological fieldwork involves exploring a space inhabited by things at the same time withdrawn and disclosed, lost and awaiting. How can a theory, or indeed any philosophy, embrace these raw things, grasp the potential for knowing already inherent in them, and thus expose itself to the threat of being affected, being redone by this very encounter?

This, we argue, is what an archaeological theory has to risk. Moreover, in order to make such a theory accountable we need to re-establish a trust in things and in experiences resulting from our mutual interactions. Learning through encounter, from things, increasingly lost weight in the theoretical tropes that characterized late $20^{\text {th }}$ century archaeology. This became further reinforced through postmodernism's hermeneutics of suspicion, where the dialectics of reading and reflection took both the front and back seat; explaining data as well as the explanation itself, which, so to speak, duplicates the futility and misgivings of grounding knowledge in things themselves. Accordingly, when establishing what counts as knowledge or is accountable for knowing, things and our immediate experiences of them became mostly reckoned with distrust and suspicion; “... as inheritors of the Cartesian legacy, we would rather put our faith in representations instead of matter, believing that we have a kind of direct access to the content of our representations that we lack towards that which is represented" (Barad, 2007: 380-81). 
Emphasizing the mobility of theory and "the practice of theorizing over theory", as argued by Lucas (2015: 28-29), represents one way to counter this bias. By flattening the relation between theory-work and other (field)work (see Edgeworth, 2012), theory is not merely something to be employed, but something to be worked on in specific empirical contexts. And, like Lucas' example of how our distinct use of the trowel has rendered it archaeological, rather than masonry, it also matters to theory what it matters for. Importantly, this is not an argument about selecting a theory that "fits" the specificity of the material, but about its morphological ability to be redefined, reworked and repaired upon encounter. Not to ignore that theories can be more and less suitable in different contexts - there is no "one-size fits all" - but it should also make a difference to theory itself whether it harbours with an account of a VOC vessel loaded with oriental goods, or among stranded plastic debris in a northern inlet. This difference is not just a difference between objects but also constitutes an archaeological difference, allowing theorizing to be initiated by the direct encounters with a tactile and unsorted world rather than its cleansed representations. As put by Karen Barad;

To embrace representationalism and its geometry or geometrical optics of externality is not merely to make a justifiable approximation that can later be fixed by adding further factors or perturbations at some later stage, but rather to start with the wrong optics, the wrong ground state, the wrong set of epistemological and ontological assumptions" (Barad, 2007: 380-81).

Theory as mobile, adrift, bumps into things of different and often unexpected kind. And it is not unmoved by these encounters. Theory and theory-work doesn't simply "add up" in a logical, foretold and orderly manner. Rather, much like marine debris and things adrift, theory is challenged, torn, transmuted and shattered by its encounters with stuff. Not in a negative way, but in a constructive, swelling manner. One just needs to think of what disciplinary drift did to structuralism and semiotics.

Based on this, an important precondition of our argument is a notion that any theory always holds potential for something more than what it was meant to be, and more than what it is doing right now ${ }^{4}$. It always comes unfinished. That is, if we consider the practice of theory application as no less an act of supplementation/building, theory may in essence be seen to partly exceed definition, prescription and finitude. An understanding that, we argue, opens for a more constructive discussion of theory and theorizing in archaeology, where

\footnotetext{
4 With credit to Grahamn Harman (2016) and his notion of an object as irreducible to its relations, and hence "more than what it is doing right now".
} 
theory may, much like drift matter, be seen to go through processes of decay, fragmentation and dispersion and where, consequently, the inferior legacy of "borrowing" may be recast in light of innovation, gentrification and repair.

\section{NOTIONS OF THEORY}

Before moving further with that discussion, however, let us briefly summarize some commonly acknowledged attributes and associations of theory and theorizing, as perceived specifically in an archaeological context. Though any such attempt at generalization inevitably runs the risk of glossing over differences and previous critiques, we still believe it is possible to identify some widely shared assumptions and expectations that deserve attention.

As an overall notion, theory in archaeology is perceived as a means by which we interpret or explain observed facts, and sometimes simply as "the order we choose to put facts in" (Johnson, 2006: 118). In the Concise Oxford Dictionary of Archaeology, the entry on archaeological theory describes it as "A body of philosophical and theoretical concepts providing both a framework and a means for archaeologists to look beyond the facts and material objects for explanations of events that took place in prehistory" (Darwill, 2008, emphasis added). Statements like this emphasize the indispensable and pivotal nature of theory, and reflect the common notion that things cannot speak "without the benefit of intervening theory" (Johnson, 2006: 129). Theory's ambitions, however, range wide, including how to explain and understand society and nature, and to provide metaphysical justification for how and why we distinguish between these realms - or, indeed, how we prefer not to do so. Theory, thus, may be viewed as both "foundational" and "revelatory" (Conkey, 2007), as a mental map or plan for how to approach and perceive something, and as an eye opener and challenge to see things differently. In the latter sense, theory is not simply "a stable set of guidelines" to be applied, but "should be thought of in terms of its effects" (Conkey, 2007: 297) and how it alters the researcher's perspective of the act and object of study. In other words, whether social, epistemic or ontological, theory is not only the means for interpreting the archaeological record, and for the knowledge we create from it, but also for critically reflecting on the practice of doing so.

A commonly conceived feature of theory, moreover, is that it occupies a sphere somehow set off from our doings and the stuff we deal with. Both in everyday semantics and scholarly conducts, theory is often seen in contrast to practices, to things and the world as immediately manifested and experienced. Despite the schism between so-called top-down and bottom-up theorizing, the elevated position of theory itself within these opposed approaches is hardly questioned. 
The same counts for the processualist and post-processualist mantra that all data is theory-laden, which despite emphasizing their interconnectedness builds upon and reinforces the hierarchy. The image of theory as situated above the empirical world, approaching it from distance, also relates directly to its assumed explanatory power. A strong theory, as noted by Silvan Tomkins, has a generality that allows it to account for "... a wide spectrum of phenomena which appear to be very remote, one from the other, and from a common source..." (Tomkins, 1963: 433). A theory not fulfilling such generality, pertaining only to few or proximate phenomena, is weak and "... little better than a description of the phenomena which it purports to explain” (Tomkins, 1963: 433).

Theory, accordingly, is mostly general and abstracted rather than situated and concrete. It may emerge from observations on the ground but its strength and explanatory success relies as much on its detachment from specific case based relations, and its perpetuation, thus, does not necessarily depend on concrete empirical verification. Allowing us to go "beyond the facts and material objects", theory becomes a means to depart from mere description, and thus to engage in the creative endeavour that is claimed to distinguish an academic archaeology from antiquarianism (e.g. Barrett, 2016). Theory, in other words, is revelatory, creates relations, unravels meanings, and also makes sense of that which otherwise is merely perceived and thus poorly understood or explained.

This leads to yet another common attribute of theory, which is the claim to coherence and consistency. Theory provides a model world, which despite also encompassing ambitions about explaining or integrating fragmentation and contradictions in its explanatory framework (such as in Marxism and structuralism), is itself, ideally, devoid of such inconsistencies (see Gero, 2007). Also for this very reason, theoretical eclecticism, mixing elements from different and even competing theory-frameworks, is met with suspicion and often seen as representing inconsistency and insufficient knowledge of the wider bodies of thinking which the elements emerge from. Closely related is the expectation of theoretical purity; that $a$ theory represents a fixed and ready-made tool-box to be applied "as is", or as faithfully as possible, without much compromises, additions, and transformations. The alleged archaeological fallacy of "theory borrowing" is at least partially based on this all-or-nothing conception, where the use of non-native theory is conceived of as a passive act of moving an already processed body of theory from a site of production to a site of application (see Lucas, 2015). This, furthermore, ascribes a finitude and confinement to theory and the act of theorizing, emphasizing its abstract loci and the absolute divide between theory and data. In fact, one might argue that the idea of finitude not only grounds a negative notion of "borrowing" but also the repeated claims to the death of theory. 
But what happens if we think theory in different terms? Not only the act of theorizing, as in replacing a top-down model with a ground-up one, but also the morphological notion of theory and theoretical bodies themselves. Is it possible to perceive them in a way that renders them less static and closed? In a way that, so to speak, acknowledges their "dark side" - their unrealised excess - and the unanticipated potentials mutually discharged through the synergy between data and theory? A way that sees theoretical bodies less as solid matters of fact and more as fragile matters of concern (cf. Latour, 2004), and as such in need for active care, maintenance and repair?

\section{THEORY AS A FRAGILE MATTER OF CONCERN}

Theory, as outlined above, may be conceived of as what Latour (1987) has called an "immutable mobile". He coined the term to grasp the effect and outcome of processes of transformation and inscription, through which something real and generally immobile (e.g. landscapes, sediments, archaeological sites, stars) is transformed into mobile and standardized ("immutable") representations easy at hand (figures, maps, tables, papers) (Latour, 1987). Contrary to many of the "raw" entities of the world, such inscriptions can be accessed without much effort and thus also be gathered and mobilized in ways that many real substances inhibit. A convenience, Latour argues, which eventually renders these phenomena immense sources of power. Being literate on such immutable inscriptions gives you the edge on those who are not, as it enables you to creatively superimpose, recombine and summarize them in ways that are not evidently perceptible or directly reflective of the material phenomena to be experienced out there (Latour, 1987: 30).

Theory, theoretical bodies, as normally perceived both in the humanities and the social and "hard" sciences, carry many of the features of immutable mobiles. Most theorists do not have to engage directly with waste, sea currents, glaciers, soils or trowels. On the contrary, inscriptions and discursive matters (numbers, statements, arguments, concepts, syntheses) are often their prime entries to the world, and theoretical practices very often take the form of commentaries on existing philosophical or theoretical statements. For example, in the currently blooming theorizing of "objects" and "things" it often appears far more significant, natural and appropriate to approach Kant or Heidegger's philosophical inscriptions than to engage concretely with chairs, sewer pipes, ruined apartment homes, stranded ships, or land fills. In other words, theories/concepts as immutable mobiles often perform as more real, appropriate and important than the multifaceted tactile entities out there. 
Fig. 2 The inlet of Eidsbukta seen from Sværholtklubben

However, rather than accepting this as a given feature or rationale of any theoretical and scholarly endeavour, we may ask what happens if we start to see theory rather as a mutable mobile? That is, as something which doesn't simply and always "add up", but holds some semblance to and even empathy with the raw and unprepared entities it strives to near - an oblique and unfinished potential that allows for intersection and exchange. What could be gained from seeing theory as situated, partial and/or provisional, and even as potentially fragile and "weak" (cf. Sedgwick, 1997)? Bearing on Eve Sedgwick's (1997) distinction between "reparative" (weak) and "paranoid" (strong) theory (or critical practices), "weak theory", according to Kathleen Stewart, is one that "comes unstuck from its own line of thought to follow the objects it encounters, or becomes undone by its attention to things that don't just add up but take on a life of their own as problems of thought" (Stewart, 2008: 72). Unlike a "strong" theory, which is paranoid in defending a pre-established conceptual and analytical correspondence with objects of the world, a reparative or weak theory becomes attuned to and by the rhythms and trajectories of these things. Its raison d'être is neither to evaluate them nor "to somehow get their representation "right"'” (Stewart, 2008: 73), but to provide a space that allows us to be moved by them and thus explore "what potential modes of knowing, relating and attending to things are already somehow present in them as potential or resonance" (Stewart, 2008: 73).

A weak theory, thus, is one that replaces suspicion and paranoia with trust and affinity, and as a result becomes vulnerable and mutable. By following things, a weak theory allows us to wonder where they might take us. In that sense, theoretical engagement (and interpretation) is not simply yet another comment on things already inscribed, but a way of reciprocal or "reparative" reasoning that becomes enriched, modified, scarred and complemented through actual encounters with things, raw and unkempt. Rather than seeing this as a defeat or fallacy that questions the very rationale of having theory at all, this should be seen as a productive potential already integral to theory and its way of attending to things. In other words, what becomes weakened is not the integrity of theory, as such, or the potential for creating knowledge, but rather the fixed notion of theory as an always-already finite whole, which morphology is set apart from its analytical matters of concern.

In fact, following Bruno Latour (2004), we might say that in this weak notion theory becomes transformed from "matter of fact" to "matter of concern"; from finite and black-boxed entities to fragile gatherings. Such theory will inevitably change and fracture when moved around and brought into contact with different 
things (cf. Latour, 2004: 237). Less concerned with adjusting these to an immutable vocabulary, it becomes moved by them in ways that accommodate their particularity; and rather than one-sidedly vocalizing things, theory itself becomes articulated through thingly encounters. In other words, the encounter with things, with alterity, becomes decisive and constructive also for theory.

\section{BEING AND KNOWING}

Implicitly, this also involves a rethinking of the relationship between theory and data in a more egalitarian way. While there has been much focus on an ontological turn also in archaeology and on how archaeological theorizing has turned ontological, become more "flat", and object-oriented (see e.g. Alberti, et al. 2013; Lucas, 2015; Thomas, 2015b; Edgeworth, 2016, Harris and Chipolla 2017), far less attention is devoted to how the altered ontological position of things and natures, affects the relationship between theory and data, the production of knowledge, and the notion of epistemology more generally. This is intriguing, since the new materialist and post-humanist perspectives for sure should create other epistemological challenges and possibilities than those emerging from a Cartesian bifurcation of the world. And though it may be true that this ontological turn has hitherto, in an archaeological context, mostly raised concern for "the materiality of our data, not its epistemic status" (Lucas, 2015: 18), it appears equitable that the possibility of knowing must be affected as well.

The persistent modern ontological divide for long rendered knowing and interpretation an act of reaching that which is beyond things, attending to a presumed extra-material domain devoid of objects and non-humans. Much epistemological and methodological debate in archaeology, such as the question of how to bridge the gap between a static archaeological record and the dynamics of past societies, has been rooted in this bifurcation and the understanding of societies and cultures as primarily humanly constituted entities. The current ontological turn has clearly opened for a different take. When no longer treated as epiphenomenal residues of society but as indispensable constituents of the world, fundamentally involved also in human conducts and social trajectories, the epistemological status of things as data cannot remain unchanged. Hence, to argue that the current paradigm shift is ontological rather than epistemological, is to overlook the entanglement of knowing and being, and may even sustain the very bifurcation that this "ontological turn" has attempted to overcome (cf. Barad, 2007: 379-80).

This rhizome character of the current theoretical turbulence relates directly to another aspect of this, which has received equally little attention: How does the fading of ontological polarities and the growing recognition of non-human 
agency actually come about? Is it likely that these changes stem solely, or even primarily, from pure reasoning, speculations, or "magical" happenings in the theorists' minds? Or is it rather the case that they emerge as a consequence of experience and knowledge gained from attending to things, to how they behave, and to what is disclosed through acquaintance with their mingled articulations? In other words, that ontology depends on knowing as much as knowing depends on being. Both are mutually and materially constituted, and, thus, to paraphrase Heidegger, "thrown" into the world; into the "There" of "whence and whither" (Heidegger, 1962: 174), and from which they cannot be divorced. As forcefully argued by Karen Barad:

"Knowledge making is not a mediated activity, despite the common refrain to the contrary. Knowing is a direct material engagement, a practice of intra-acting with the world as part of the world in its dynamic material configuring, its ongoing configuration. The entangled practices of knowing and being are material practices.... To the extent that humans participate in scientific or other practices of knowing, they do so as part of the larger material configuration of the world and its ongoing open-ended articulation" (Barad, 2007: 379, our emphasis).

The way things increasingly have articulated themselves as "always-already" blending with other things, humans and natures, forming innumerable interacting units and collectives, and refusing to orderly "add up", was clearly vital for the emerging disintegration of the Cartesian legacy. Ever more pressingly confronted with messy assemblages weakened the cohesion of this prevailing ontology, and what previously appeared as finite matters of fact gradually stood out as important matters of concern (Latour, 1993, 2004).

Concern, awareness and knowledge created in response to these material articulations should therefor also be seen as decisive for rethinking other aspects pertaining to things' being. Consider for example Graham Harman's proposition regarding things' autonomy from their yet inextricable entanglement in webs of relations and interactions, and the related notion that they are always more than what they are doing and thus not exhausted by use and human intentions (Harman, 2002, 2016). While sympathizing with his position, a crucial question is still how one can arrive at such understandings, become convinced about their truthfulness, without seeing knowing and being as entangled in material practices and as interactively constitutive of each other? How can one know so much about things' being and at the same time claim it to be non-knowable? (Harman, 2016: 17). This is not to say that knowledge of their being by any means can be exhaustive; in fact, it will probably always be partial, preliminary and to some extent uncertain. But to acknowledge things' autonomy, resistance, and reservoir of potential still requires attentiveness to their "open-ended 
articulations" and to how they thereby become "problems of thought". Thus, far from being beyond or "above" ("meta") the "material" ("physics"), ontology itself emerges from a "thrown" condition and is morphed in responsiveness to matter (cf. Gumbrecht, 2004: 22).

This we find crucial for how to conceive of theory, its formation and immediate connection to the world; in other words, how it comes into being. And it is the palimpsest relationship between theory as a mutable mobile and a fragmented, differentiated world, that needs to be retained; both as pertaining to the internal fragility of the theoretical body, and with respect to its enmeshment with an equally fragile and unfinished world. Because, as so eloquently stated by Kathleen Stewart, "matter in an unfinished world is itself indefinite - a not yet that fringes every determinate context or normativity with a margin of something deferred or something that failed to arrive, or has been lost, or is waiting in the wings, nascent, perhaps pressing" (Stewart, 2008: 80). Attaining to this unfinished world may seem futile and unpromising, especially as compared to the neat and coherent representations that most theories and philosophical reasoning put their faith in. Yet, it is this unfiltered world, that is constitutive of our being and accountable for our knowing.

$<<$ INSERT FIGURE 3 ABOUT HERE >>

Fig. 3 Entangled drift matter in Eidsbukta

\section{LESSONS FROM DRIFT}

"[H]ammers aren't exclusively for hammering. Apparent functioning is subtended by malfunctioning" (Morton, 2012: 98)

Let us return again to our Arctic inlet and the swell of stuff on its shore. We asked at the beginning of the article what forms of knowing these things might make possible, and how their being and bulging might affect our advancing - and our theorizing? As we explained, but is possibly articulated more strongly through the verse of photography (see figures 1-5), the weighty and unruly presence of these things on a today humanly abandoned shore, in many ways defies accustomed archaeological reasoning. Notions of cultural context and meaning become baffled, and though many things may indeed be recognized by name and function, and even retraced to sources and human relations, what appears most authentic and genuine about this stuff is its post-human drift. What it has become beyond the measures of the human. In other words, what the possible familiarity and recognition of things recalls on encounter is not so much a known and familiar past as an utterly unexpected and unfamiliar future; how things have drifted out of past associations, and become fragmented, detached and transmuted in ways not foreseen. 
So, how do we attend to such things that do not just add up, and in ways that also don't just add up, but allow us to be moved by their being and to explore modes of knowing that "are already somehow present in them as potential or resonance" (Stewart, 2008: 73). How should we take the material seriously as it presents itself here and now? One aspect of this responsiveness is to acknowledge the realness of these articulations, and how these stranded things have taken on "a life of their own as problems of thought" (Stewart, 2008: 73); a "life" that defies but also suggests ways of theoretical proceedings. For example, encountering hybrid assemblages of sea-borne things, it is indeed hard not to think of their resistance and autonomy in relation to our intentions, prospects and programs. Many of them have travelled long distances, spent years at sea, and been to places unheard of - they have abandoned their human companions and their intentions for them, established new alliances, and many of them will surely outlive us. Considering, the autonomy and unpredicted futures of these drifting things, in what way can we sustain a notion of the present as the outcome of a solely human past? To what extent can we claim that things are innocent beings, reducible to simple means towards our ends? And given the blatant exposure of their unruliness, how do they affect the way we think about objects more generally, including their agency, life and affordances?

\section{$<<$ INSERT FIGURE 4 ABOUT HERE $>>$}

Fig. 4 Drifting masses in Eidsbukta, with Sværholtklubben cape in the background

Indeed, things have been thoroughly theorized in philosophy and elsewhere. Their agency and ability to act has been dealt with by Alfred Gell (1998) and Bruno Latour $(1987,2005)$, their social life has been theorized by Igor Kopytoff (1986) and Arjun Appadurai (1986), their affordances by James Gibson (1986), their entrenched power by Jane Bennett (2010), their affect by Brian Massumi (2002), and their ontology by Martin Heidegger (1962), Graham Harman (2002, 2016) and Levi Bryant (2011), to name a few. But how does the artwork in Gell's theorizing articulate installations on an Arctic shore? How do concepts like decommodification, social life, vitality or waste work with these vagabonds? And what happens to already articulated notions of affect, affordance and, indeed, agency, when juxtaposed with these drifting things? As we have argued, it matters to theory what it matters for; agency, as an example, is not - should not be the same when weighed against artworks, citizens' with guns, VOC vessels, or drift matter. Harbouring in new territories, encountering new things, affects theory. It quivers and loosens and reveals its fragility, but equally so its ability to spill over, swell and grow into novel and unforeseen directions. Hence, a theory of agency becomes pruned and enriched through an encounter with drift matter. 
While human involvement and inter-action may have been significant to its articulation on different soils, these attributes lose their gravity or pendulum on an uninhabited Arctic shore. This is not to scorn the significance and originality of the works of Gell, Latour and others, but to emphasise three related points; firstly, that the "example", the matter of concern, is central to theory and to what theory becomes; secondly, that theory, for that very reason, is fragile, attentive and "weak" for what it matters for; and, thirdly, that theory, thus, is always more than what it is doing right now. The wealth of its affordance cannot be foreseen at the outset or in any one case study.

Moreover, and importantly, this fragility and weakness is also what keeps theory alive. It is not a weakness in the negative sense of a disadvantage or flaw, but rather in the sense of an affinity, an empathy and even enduring affection for the unfamiliar and other. Hence, this also adorns theory and theorizing with a crucial ethical aspect; theorizing is not a matter of conquest but a cautious process of exploring tensions, potentials and future trajectories for both things and concepts, by putting both at risk. Think again of the amalgam of stuff stranded in our Arctic inlet - though much of it may be recognizable and familiar, it all appears novel and other on this new terrain. Things are at the same time detached, transmuted, torn, woven, skirted in ways that could not be foretold, many of them fragmented and deformed. However, and as recalled in the assembly's partial familiarity, this recasting is not realized so much by way of substitution as by persistency, drift and disclosure. Things remain, but reveal themselves differently. When divorced from previous human relations and usefulness, things not only become exposed to other trajectories and futures, but also expose some of their own otherness. When met on the beach they reveal sides of their being that remained hidden or withdrawn while acting within the network of a "homely repertoire". Here, in their stranded redundancy, they show themselves differently - and we are able to see them differently.

We may think of theory in very much the same manner. While comfortably moving within the confines of a human society, reverberating exclusively human relations and intentions, agency theory may be extremely fruitful, but is able only to swell so far. However, when brought out of this milieu and into, for example, a more or less human devoid archaeological context, not to mention a post-human context like the one being shaped in our Arctic inlet, agency theory shows itself differently - and we are able to see it differently. What functioned well in a previous context, like the significance of delegation and distributed personhood (Gell, 1998; Latour, 2005), here faces friction and juxtaposition in new encounters. And while this may be seen as fallacy, a theory out of place and unfit for the challenges encountered, it may also more productively be seen as opening up alternative agental vistas and other accentuations. It is this ability, this weakness, we claim, that makes theory work; its resilience and indeed 
development depend on its dialectics of functioning and mal-functioning (cf. Morton, 2012).

Like things, theory doesn't simply add up and make sense. Rather, much like other things washed up on a beach, theories, such as agency, becomes polished, nuanced, turned and transfigured. And in order to function it must be allowed also to malfunction and thereby disclose otherwise hidden aspects of its being. Following this we may even argue for theory, what Harman argues for objects; that it "is better known by its proximate failures than by its success" (Harman, 2016: 116). And, while often insinuated as a rational act of constructing coherency and logic, theorizing is as much an act of being attuned to and staying with trouble (cf. Haraway, 2016), to see where it may lead. Or, as argued by Timothy Morton (2012); "Mastery could superficially mean knowing how the tool functions so well that I don't have to think about it ... Yet mastery could also be about realizing that functioning is a special kind of malfunctioning to which I'm not attending enough. So mastery could be allowing things to malfunction" (Morton, 2012: 103). Hence, mastering theory, borrowing theory, in other words theorizing, can be seen as an act of exposing theory to new vistas, and allowing it to malfunction in order to sustain its legacy.

If theory was a finite black-boxed entity, hovering above and enlightening a presumably uncharged world down there, it becomes difficult to explain its survival and legacy beyond the momentary. But by acknowledging how theory and things interact, and the many similarities between the two, it becomes possible to explore the full complexity of theoretical morphology, a richer and more tangible pedigree of theoretical development, and how a "parasitic" discipline like archaeology importantly contributes to that swelling.

\section{TO CONCLUDE: IN DEFENCE OF AN ART OF BORROWING}

Our approach in this article has been morphological; that is, our focus has been on how theories are conceived of and structured and how this affect the way they work and behave. We suggested at the outset that the very notion of theory, as prevailing in archaeology, needed a rethinking and we have explained what this implies and why it is of significance. It is pertinent to accentuate, moreover, the very archaeological grounding of that rethinking. Our argument does not merely benefit from a reference to things, but has literally been borne and developed out of engagements with drift matter in a northern inlet and through many other studies of archaeological assemblages, new and old. As we have stated, though strongly accentuated by the tumbled and torn masses of marine debris, the thingly characteristics radiated here are in fact shared with much of the archaeological more generally. Fragmentation, decay, inconsistency, 
detachment and entanglement are not so much the "problems" archaeology deals with on daily basis, as the nuances that actually constitute our craft. And what we wished to bring forth through this article is that this not only holds true for our literal fieldwork and dealings with things, but also for how we "borrow" and work with theory.

$<<$ INSERT FIGURE 5 ABOUT HERE $>>$

Fig. 5 "Trownness": Drift matter in Eidsbukta

We sympathize with scholars arguing for the indispensable nature of theory and theorization as part of archaeological work. However, we have sought to undermine the common notion (and the implied hierarchy) that things cannot speak "without the benefit of intervening theory" (Johnson, 2006: 129), as also expressed in the almost ontologized notion that all data is theory-laden. By emphasizing the morphological aspects of theorization, we have argued that theory cannot articulate itself without an intimate engagement and empathy with the world. This may very well be revelatory for how things work, but things are no less revealing for theory and theoretical function/malfunction. Therefore, and importantly, this is not merely a matter of "reference" or "examples", but rather of how theory is part of the world, is "thrown" into it, and, thus, much like the objects it seeks to frame, fragmentary, polluted and eclectic.

Like drift matter on an Arctic shore, theories are adrift. They are not natives confined to any particular territory, but nomads in a mixed world, always accommodating themselves to shifting local conditions. While they are themselves of certain weight and figure, and inimitable and irreducible in that sense, it matters what they matter for; it matters what things they bump into, what networks and meshworks they become entangled in. We may think of this in line with Manuel DeLanda's explanation for the partial autonomy of individual parts in assembled action. It is important, DeLanda (2006: 10-11) argues, not to conflate a thing's (here: theory's) characteristic properties with its capacities to interact with other entities. While the former may be known or rateable, though even this may be relative, the latter cannot be grasped or foretold at any given moment. That is, though dependent on its properties, a theory's capacity to act cannot be reduced to those, since its realization refers to interaction with properties and capacities of other entities. Therefore, as capacities of becoming may partly be seen as afforded by a theoretical body or concept - already resting in its "physique" - its actual becoming is realized only through association with things, with the world, which adds an aspect of volatility to its potential future. Any theory is more than what it is doing right now. It has a "dark side", an unforetold excess, that only becomes discharged through drift and through the synergy emerging from new encounters. Hence, like other nomads of uncertain terrain, it isn't so much the point of origin that matters as the drift and 
encounters with ever new territories, ever new things, that becomes telling for a theory's legacy and potency. Borrowing, is an art of keeping theory alive.

\section{REFERENCES}

Alberti B, Jones AM and Pollard J (eds) (2013) Archaeology After Interpretation: Returning Materials to Archaeological Theory. Walnut Creek: Left Coast Press.

Appadurai A (ed) (1986) The Social Life of Things: Commodities in Cultural Perspectives. Cambridge: Cambridge University Press.

Barad K (2007) Meeting the Universe Halfway: Quantum Physics and the Entanglement of Matter and Meaning. Durham: Duke University Press.

Barrett J (2016) The New Antiquarianism? Antiquity 90(354): 1681-1686.

Bennett J (2010) Vibrant Matter: A Political Ecology of Things. Durham: Duke University Press.

Bintliff JL and Pearce M (eds) (2011) The Death of Archaeological Theory? Oxford: Oxbow.

Bryant L (2011) The Democracy of Objects. Ann Arbor: Open Humanities Press.

Bryant L (2016) Examples. In: Larval Subjects. Available at: https://larvalsubjects.wordpress.com/2016/07/27/examples/ (Accessed 20 June 2017)

Conkey MW (2007) Questioning Theory: Is There a Gender of Theory in Archaeology? Journal of Archaeological Method and Theory 14(3): 285-310.

Darwill T (2008) The Concise Oxford Dictionary of Archaeology. Oxford: Oxford University Press.

DeLanda M (2006) A New Philosophy of Society: Assemblage Theory and Social Complexity. London: Continuum.

Edgeworth M (2012) Follow the Cut, Follow the Rhythm, Follow the Material. Norwegian Archaeological Review 45(1): 76-92.

Edgeworth M. (2016) Grounded Objects: Archaeology and Speculative Realism. Archaeological Dialogues 23(1): 93-113. 
Gell A (1998) Art and Agency: An Anthropological Theory. Oxford: Oxford University Press.

Gero JM (2007) Honoring Ambiguity/Problematizing Certitude. Journal of Archaeological Method and Theory 14(3): 311-327.

Gibson JJ (1986) The Ecological Approach to Visual Perception. New York: Psychology Press.

Gumbrecht HU (2004) Production of Presence: What Meaning Cannot Convey. Stanford: Stanford University Press.

Haraway D (2016) Staying With the Trouble: Making Kin in the Chthulucene. Durham: Duke University Press.

Harman G (2002) Tool-Being: Heidegger and the Metaphysics of Objects. Chicago: Open Court.

Harman G (2016) Immaterialism: Objects and Social Theory. Cambridge: Polity Press.

Harris OJT and Chipolla CN (2017) Archaeological Theory in the New Millenium. Introducing Current Perspectives. London: Routledge.

Heidegger M (1962) Being and Time. New York: Harper and Row.

Johnson M (2006) On the Nature of Theoretical Archaeology and Archaeological Theory. Archaeological Dialogues 13(2): 117-132.

Kopytoff I (1986) The Cultural Biography of Things: Commoditization as Process. In: A. Appadurai (ed) The Social Life of Things: Commodities in Cultural Perspectives. Cambridge: Cambridge University Press, pp.64-91.

Kristiansen K (2014) Towards a New Paradigm? The Third Science Revolution and its Possible Consequences in Archaeology. Current Swedish Archaeology 22: 11-34.

Latour B (1987) Science in Action: How to Follow Scientists and Engineers through Society. Cambridge, Mass.: Harvard University Press.

Latour B (1993) We Have Never Been Modern. Cambridge, MA: Harvard University Press.

Latour B (2004) Why Has Critique Run out of Steam? From Matters of Fact to Matters of Concern. Critical Inquiry 30: 225-248. 
Latour B (2005) Reassembling the Social. Oxford: Oxford University Press.

Lucas G (2015) The Mobility of Theory. Current Swedish Archaeology 23: 13-32.

Massumi B (2002) Parables for the Virtual: Movement, Affect, Sensation. Durham: Duke University Press.

Morton T (2012) Mal-Functioning. The Yearbook of Comparative Literature 58: 95-114.

Sedgwick EK (1997) Paranoid Reading and Reparative Reading: Or, You're so Paranoid, You Probably Think this Introduction is About You. In: E. Sedgwick (ed) Novel Gazing: Queer Readings in Fiction. Durham, N.C.: Duke University Press, pp.1-40.

Stewart K (2008) Weak Theory in an Unfinished World. Journal of Folklore Research 45(1): 71-82.

Thomas J (2015a) Why "The Death of Archaeological Theory"? In: C. Hillerdal and J. Siapkas (eds) Debating Archaeological Empiricism: The Ambiguity of Material Evidence. London: Routledge, pp.11-31.

Thomas J (2015b) The Future of Archaeological Theory. Antiquity 89: 12771286.

Tomkins S (1963) Affect, Imagery, Consciousness. New York: Springer. 